\title{
Nobreza e fidalguia. El vocabulario del honor en el Portugal de los Habsburgo
}

\author{
José Antonio GuILLÉn BerRendero* \\ CIDEHUS-Universidad de Évora \\ jagberrendero@hotmail.com
}

Recibido: 11 de noviembre de 2009

Aceptado: 19 de mayo de 2010

\section{Resumen:}

El presente artículo analiza la forma en que el vocabulario sobre el honor en el Portugal Habsburgo resultó una realidad transversal al lenguaje o lenguajes existentes en el ámbito de la Monarquía Española. La existencia de términos semejantes y la permeabilidad de los mismos en diferentes escenarios políticos permitieron poder hablar de nobles y noblezas dentro de la configuración de un ideal typus nobiliario que dominó Europa. La forma en que conceptos como hidalguía y fidalguia remiten a realidades discursivas semejantes y permitieron la perfecta asimilación de las élites nobiliarias lusas dentro del proyecto de la Monarquía en los años de la Agregação.

Buscar las semejanzas existentes en el discurso nobiliario entre las variables discursivas del Portugal Habsburgoyeliminarposiblesantagonismosentreconceptoscomonobre-fidalgo, parainsertarlaproducción discursiva sobre la nobleza en el Portugal de los felipes dentro de las líneas y corrientes de pensamiento basilares de la condición e identidad nobiliaria. Porque la idea de nobleza en Portugal durante el periodo 1580-1640 se articuló en base a la idea de preeminencia social, limpieza de sangre y limpieza de linaje, lo que terminó por establecer un vocabulario sobre el honor en el que las categorías nobiliarias quedaban sometidas a la potencia expresiva de términos como honrado, noble, ilustre y o la categoría de vivir a lei de nobreza.

Esos son los tópicos centrales que manejamos en este artículo, desde la idea de una unión de discursos que identificó las formas de comunicación que sobre lo nobiliario se desarrollaron en la Monarquía Española durante la Edad Moderna.

Palabras clave: Nobleza, honor, Portugal, discurso nobiliario.

\section{Nobreza e fidalguia: The vocabulary of honour in Habsburg Portugal}

\begin{abstract}
:
This paper explores the vocabulary of honour in Habsburg Portugal as a transversal reality to the existing language (or languages) within the framework of the Spanish Monarchy. The existance of similar terms and their permeability in different political scenarios allow us to talk of noblemen and

\footnotetext{
${ }^{*}$ Becario Pos-Doctoral de la Fundação para a Ciência e a Tecnologia, Ministério da Ciência, Tecnologia e Ensino Superior del Gobierno de Portugal com el proyecto Os agentes da Honra em Portugal e Castela, 1640-1750: reis de armas e Comissários das Ordens e respectivas redes sociais. Ref. SFRH/BPD/44883/2008 Investigador Integrado en el CIDEHUS-Universidade de Évora.Agradecer el tiempo que Nani dedicó a leer este trabajo y enmendar algunos errores. Alma de la Biblioteca Nacional de Madrid. Igualmente a Susana por su puesta al día de los asuntos lusos.
} 
nobilities within the noble ideal typus which dominated early modern Europe. Concepts such as the Spanish term hidalguia and the Portuguese fidalguia referred to a similar discursive reality and this facilitated a perfect assimilation of the Portuguese nobility into the project of the Spanish Monarchy in the years of the so-called Agregação.

The main objective of this research is to explore these similarities and to cancel potential conflicts between concepts such as nobre-fidalgo, in order to integrate the discursive production of the nobility in Philippine Portugal within the lines and basic currents of thought of the nobility's status and identity. From 1580 to 1640, the idea of nobility in Portugal was based on social prominence and blood cleaning, and this ended up establishing a vocabulary of honour in which noble categories were subject to the eloquent power of terms like honrado, noble, ilustre or the category of vivir a lei de nobreza ('to live according the nobility's laws'). These are the issues we deal with in this contribution, with the central idea of a union of common discourses that identified the forms of communication on nobility developing in early modern Spanish Monarchy.

Key words: Nobility, honour, Portugal, nobility discourse.

\section{Referencia normalizada}

Guillén Berrendero J. A. (2011). "Nobreza e fidalguia. El vocabulario del honor en el Portugal de los Habsburgo". Cuadernos de Historia Moderna, Vol 36.: pp. 41-66

\section{“Enseñome Aristóteles que la lengua era intérprete del coraçón”}

El lenguaje sobre la nobleza o lo nobiliario, en cualquiera de sus niveles jerárquicos, se construye como reflejo normativo del deseo por establecer categorías que caractericen y profundicen en los modelos clásicos creados en torno a lo nobiliario ${ }^{2}$. Esto ocurre con independencia de otras cuestiones tales como la distinción entre nobres e fidalgos que adquirirán, al igual que en Castilla, una mayor importancia a lo largo del siglo XVIII y sobre todo del burgués siglo XIX. En tanto que el vocabulario sobre la nobleza responde tanto a una tradición secular de índole jurídica y de derecho natural, como a un conjunto de urgencias de tipo político, imperial si se quiere, resulta importante percibir la forma en que a lo largo de la Edad Moderna se fue fijando un modelo explicativo para todas las manifestaciones nobiliarias. Palabras latinas, griegas que al socaire del humanismo intentaron explicar la comunidad de intereses y la similar naturaleza de la condición de

${ }^{1}$ LOBKOVITZ, Juan de Caramuel: Respuesta al Manifiesto del Reyno de Portugal, Amberes, 1642, fol. I.

${ }^{2}$ Es amplia la bibliografía sobre el lenguaje y su influencia en la política y las relaciones entre la cultura manuscrita y la impresa. Remitimos a algunos textos esenciales para profundizar en algunos aspectos que pueden ayudar al lector a contextualizar este nuestro trabajo: CURTO, Diogo Ramada: O discurso político em Portugal (1600-1650), Lisboa, 1988. BUESCU, Ana Isabel: "Cultura impressa e cultura manuscrita em Portugal na época moderna: uma sondagem”, Penélope, 21 (1999), pp. 11-32. BOUZA, Fernando: Corre manuscrito. Una historia cultural del Siglo de Oro, Madrid, 2002. Y también su texto Comunicación, conocimiento y memoria en la España de los siglos XVI-XVII, Salamanca, 1999. CORFIELD, Penelope (ed): Language, history and class, Oxford, 1991. THOMPSON, Irwing A.A: "Non-Noble nobility: Concepts of hidalguia in Early Modern Castile", European History Quarterly, 15-4 (1985), pp. 379-406. Y, del mismo autor, "Hidalgo and pechero: the language of states and classes in early modern Castile" en CORFIELD, Penelope (ed.): Language, history and class, Oxford, 1991, pp. 53-78. O la clásica obra Hidalgos \& hidalguias dans l'Espagne des XVIe -XVIIIe siècles. Theories, practiques et represéntations, Paris, 1989. 
privilegiado.Lares-publicanobiliorum teníasupropiovocabulario, excluyente,speculum del conjunto de calidades colectivas particularizadas en la idea de nobleza.

Una reflexión sobre el vocabulario nobiliario es también una forma de acercarse al lenguaje político $\mathrm{y}^{3}$ a la forma en que las palabras servían como medio de exclusión social en tanto que, solamente unos pocos eran merecedores de los epítetos, premios y términos elogiosos de su condición ${ }^{4}$, cuando no eran los verdaderos sujetos activos de la memoria y de la historia de sus respectivos reinos ${ }^{5}$.

Desglosaremos a lo largo de estas páginas un conjunto de reflexiones derivadas de la consideración inicial que sitúa al vocabulario en torno al honor y a lo nobiliario dentro de la esfera de la idea de excelencia, la preeminencia social y cómo las diferencias de matiz entre términos como fidalguia e hidalguía terminan por convertirse en asuntos terminológicos más que en categorías sociales diferenciadas. La consecuencia es que el análisis de cualquier discurso sobre la nobleza y su predominio social durante la Edad Moderna posee, indistintamente de la realidad política y geográfica, una arquitectura que confiere a los argumentos una solidez que permite su utilización en el tiempo largo.

Escribía en los tumultuosos años de la Restauração, don Juan de Caramuel Lobkovitz, Abad de Melrosa y Vicario General de la Orden del Cister para los Reynos de Inglaterra, Irlanda y Escocia, un texto titulado Respuesta al manifiesto del Reyno de Portugal. ${ }^{6}$ La obra está dedicada a don Francisco de Melo, conde de Assumar, a la sazón consejero de Estado de Felipe IV. En el prefacio al lector, el abad ofrece un panorama general sobre la nobleza portuguesa en el que podemos encontrar un conjunto de términos y expresiones que, además de estar escritas en castellano, vinculan el origen de la nobleza lusitana a la de los reyes. El primer argumento de su discurso se centra en elogiar la labor de la "nobleza portuguesa" a la que define como: "cuerda, benigna, prudente y próvida en su consulta y resoluciones. Pero en la ejecución de sus decretos, no sólo es generosa, sino temeraria también algunas

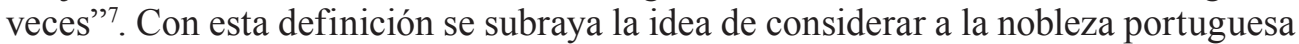
con el axioma, "valor y brío de caballeros portugueses" ", asimilando los dos términos (nobles y caballeros) para reforzar la idea de calidad.

Continúa su elogio apoyándose en el concepto de magnanimidad: "apoyo son de su brío más que humano, efectos de su magnánima temeridad". Grandeza de ánimo y generosa actitud que, en opinión de Lobkovitz, les ha llevado a conquistar Brasil, la India e incluso Alcácer Quibir y que aparece revestida de un halo de espíritu noble. Este vocabulario se utiliza para ensalzar a la vieja nobleza y sus valores,

${ }^{3}$ CURTO, Diogo Ramada: Cutura escrita (séculos XV-XVIII), Lisboa, 2006, p. 69.

${ }^{4}$ Para algunas formas de tratamiento véase el texto de CINTRA, Luís F. Lindey: Sobre formas de tratamento na língua portugueza, Lisboa, 1972.

${ }^{5}$ CURTO, op. cit. (nota 3), pp. 91-118. Del mismo autor, "Língua e memória" en MATTOSO, José (dir.): História de Portugal, vol. III: No alvorecer da modernidade, Lisboa, 1993, pp. 357-373.

6 LOBKOVITZ, op. cit. (nota 1) f.1

${ }^{7}$ Ibidem, f.1

${ }^{8}$ Ibidem, f.1

${ }^{9}$ Ibidem. 
determinados éstos por la idea de lealtad y justicia para con su soberano legítimo que, en 1640 ha sido "agraviado" por un conjunto de "amotinados" que cometen una falta grave contra "las ceniças de sus antecesores, que fueron fidelísimos, y en empleos militares de hazienda y personas, ganaron opinión y fama" ${ }^{10}$.

Encontramos en esta breve declaración un asunto capital a la altura de 1640: la fidelidad a un monarca legítimo (pues fue jurado por las Cortes), descendiente de monarcas legítimos que concedieron gracias y mercedes a individuos, introduciéndolos en el sistema del honor, con lo que el agravio de los amotinados también se hace contra la idea misma de herencia y de la transmisión de los valores por la sangre. Poniendo en jaque los mecanismos tradicionales del sistema del honor y obligando a generar un discurso de antagonismos entre aquellos denominados valerosos y caballeros por un lado y los amotinados de otro: "hazen-le también a valientes soldados y generosos caballeros, que en diversas provincias sirven oy al Rey Nuestro Señor, conservación la authoridad de la nación que un vulgo ruin desacredita" $"$.

El antagonismo, noble- no noble, es sustituido ahora por el de noble-ruin, siendo los primeros los fieles a Felipe IV y los segundos todos los "amotinados". Así entre los primeros, el abad sitúa: "El duque del Caminho, el marquez de Vila-real, el Arçobispo de Braga, el conde de Val do Rey, el conde de Armemar, el conde de Castanheira, el Obispo de Malaca, Antonio de Mendoza, Paulo Pores de Carvalho y su hijo, Gonçalo Pires y Sebastián Pinto, su hermano, Luis da Breu de Freitas, don Agustín Manoel, Paulo Carvalho, Sebastían Carvalho, su Hermano. Antonio Correa, Diego Resende de Sousa, Iorge Gomes Alamo, su hijo. Belchior Correa da França, Pedro Baessa, Christobal Caminha, Iorge Fernandes de Luar, Matias de Alburquerque, Simón de Sousa da Moeda" 12 , todos ellos unidos por el lazo inquebrantable de "su fidelidad" y de "su sangre"13.

Las palabras que definen sus conductas engloban por igual a caballeros, nobles y no nobles. Es la lealtad el argumento de calidad que sitúa a unos por encima de los otros; declaración de principios determinada por los acontecimientos históricos de 1640, pero que también remite a una forma de entender y percibir el mundo del honor ya que, de cualquier forma, los "amotinados" quedaban excluidos de cualquier acceso al honor legítimo, ya que no son dignos de alabanza. Esta consideración político-moral sobre la condición de algunos individuos es continuada por el autor, comentando abiertamente el Manifiesto del Reyno de Portugal y las que, a su juicio, son imprecisiones históricas, legales y políticas, pues "sepa el mundo que el Duque de Bergança es Rey intruso"14 o, lo que es lo mismo, "que el vulgo que le aclama es traydor, que la poca nobleza que le sigue es infiel, y que los monarcas que le asisten son cómplices de su delito" ${ }^{15}$. Se construye un anti modelo de noble y se identifican los actos contrarios al acceso al sistema del honor. Un avatar político de la dimensión de

\footnotetext{
${ }^{10}$ Ibidem.

${ }^{11}$ Ibidem.

${ }^{12}$ LOBKOVITZ, op. cit. (nota 1) f.1

${ }^{13}$ Ibidem.

${ }^{14}$ Ibidem, f.1.

${ }^{15}$ Ibidem.
} 
los acontecimientos de 1640 en Portugal originó una amplísima circulación de textos propagandísticos tanto de los leales a Felipe IV como de los partidarios del Duque de Braganza. La fuerza de la idea de traición es tal, que en muchos aspectos recuerda a la antinomia virtud-vicio. El dualismo traición-fidelidad genera un vocabulario moral que deslegitima a los traidores frente al resto de la comunidad y sacraliza a los fieles, enriqueciendo su valoración política en un tiempo largo.

Que en 1642 se defienda e identifique la fidelidad y la magnanimidad como muestras indiscutibles de nobleza y que, el esfuerzo y valor se signifiquen igualmente como realidades de todos aquellos integrados en el sistema del honor, debe hacernos pensar en la existencia de un discurso y de un vocabulario que, desde los inicios del siglo XVI, vendría a significarse como fundamental en las estrategias de legitimación de todos los llamados a formar parte del honor político y, por extensión, de todos los miembros del estamento privilegiado.

El vocabulario manifiesta una clara afectación hacia los que mantienen un comportamiento adecuado a su jerarquía dentro del sistema del honor e indica cómo algunos términos confieren un statu quo significativo a unos individuos frente a otros. La forma en que las calidades y cualidades de unos frente a otros son representadas y comunicadas es el eje central que articuló las relaciones de poder durante el Portugal Habsburgo y en el inmediatamente posterior.

El asunto de la fama de los nobles y las ideas anejas a esta consideración circularon como categorías del lenguaje y de la representación. La exaltación simbólica que produjo la llegada a Madrid de los condes de Tarouca y sus familias con posterioridad a la "rebelión", fueron narradas con alborozo por el anónimo autor del manuscrito, Relación de servicios de d. Juan de Alarcón, Conde de Torres Vedras. Se dice que: "vinieron después a esta corte [Madrid] por horden de Su Magestad traiéndolas por todo el camino con grande ostentación y con fiestas y entradas públicas en todos los lugares por donde entraron con tanto regocijo y aplauso de todos los pueblos, que en todos, se juntaba grande concurso con aclamaciones y alabanza de la fineza de la acción"16. Se celebra la llegada de individuos nobles, de miembros de una familia reconocida por su fidelidad al monarca. Esta fama justifica la existencia de un programa festivo realizado para mayor gloria de la idea de nobleza. Nada importa si se trata de titulados, o no titulados, se premia la calidad de las virtudes personales del conde.

Para la edición de las Noticias de Portugal de Manuel Severim de Faria que don José Barbosa realizó en 1740, dice en el prólogo al lector que uno de los motivos que le llevó a "augmentar" el texto del Chantre de la Catedral de Évora, fue que "he o da nobreza em que se mostra a origen dos Appellidos e Brazoens de cada huma das Familias do Reyno, noticia tão desejada, e tão oculta a quasi todos os que de Nobreza tratarão, como se ve de sus escritos" ${ }^{17}$. Ninguna mención a clasificaciones, jerarquías, privilegios, ni tan siquiera a una diferente consideración del término

${ }^{16}$ Relación de los servicios de don Juan Suárez de Alarcón, Conde de Torres Vedras, BNE, Ms. 10475, f. 160 r.

${ }^{17}$ José Barbosa, en el Prólogo al Lector, en FARIA, Manuel Severim: Noticias de Portugal, Lisboa, Antonio Isidoro da Fonseca, 1740, s/p. 
nobre-fidalgo. El vocablo noble posee en sí mismo, incluso para los lectores del siglo XVIII, un capital más allá de simbólico, que sitúa al lector rápidamente frente al conocimiento de un grupo reconocido, prestigioso y prestigiado por la tradición secular lusitana y por la significación permanente que lo nobiliario como categoría política alcanzó durante toda la Edad Moderna.

La idea de que la nobleza es un grupo social con una trascendencia cronológica que se extiende más allá de su propia existencia se encuentra manifestada en todas y cada una de sus representaciones discursivas y políticas. El tenor de estas acciones junto con la labor de sus agentes convierte la difusión del vocabulario sobre la nobleza en un asunto de capital importancia para comprender la dimensión cultural que lo nobiliario representó en Portugal durante toda la Edad Moderna. Tanto antes de 1640 como después, muchas serán las obras y los autores e, igualmente, muchos serán los que, movidos por el deseo de insertarse en el sistema del honor, jueguen sus estrategias de legitimación y acción política con el único fin de singularizarse y formar parte del grupo hegemónico. Para ello, apoyados en la capacidad de comunicación de la imprenta y en la difusión de materiales manuscritos, recurrirán a la elaboración de documentos y textos a fin de justificar peticiones, argumentar situaciones o legitimar propiedades, títulos. Se creará un discurso con un vocabulario que, más allá de los procedimientos administrativos reglados, servirá para codificar los componentes singulares del sistema del honor, elementos que cohesionan y difunden las trayectorias vitales de cualquiera de los individuos involucrados en el acceso al honor, sean titulados fidalgos de cota de armas o cualquiera de las situaciones de la jerarquía nobiliaria portuguesa.

Se glosan y explican situaciones que afectan a la dimensión pública y privada de los individuos, se ofrecen referencias al pasado propio y al ajeno, se vinculan los actos de uno con los de sus antepasados o, simplemente, se resaltan los aspectos más relevantes de la personalidad de uno como miembro de una familia frente al resto; todo ello recurriendo al uso de un vocabulario marcado por los límites intelectuales de su tiempo y la tutela de la iglesia y que manifiesta las tensiones entre lo individual y lo colectivo.

Es un hecho capital conocer cómo fue transmitida la operatividad social del vocablo nobre o fidalgo para referirse a todos los incluidos dentro de lo que venimos a llamar sistema del honor. Libros impresos, manuscritos, toda suerte de libelos, expedientes y probanzas recurren al epíteto nobre para expresar una realidad que afecta no sólo a titulados sino a todos cuantos forman parte de esa realidad sistémica que conocemos como nobleza. La nobleza es la promotora de una transmisión cultural y simbólica, impresa, manuscrita o cincelada en piedra o diseminada entre las pinceladas de pintores. El noble, lo nobiliario, es un "hombre tipográfico"18, y las palabras para definirlos son igualmente "tipográficas", pero no sólo están afectas por esta condición. Comencemos por identificar un término que puede llamar a confusión y que puede estar relacionado con el fenómeno del bilingüismo: la relación entre nobre-noble y fidalgo-hidalgo.

${ }^{18}$ Término utilizado por la profesora Buescu. BUESCU, Ana Isabel: Memória e poder. Ensaios de história cultural (séculos XV-XVIII), Lisboa, 2000, p. 31. 
Todos los estratos jerárquicos de la nobleza portuguesa tienen dos signos evidentes de distinción, "antiguidade e clareza"19. La trascendencia temporal de la condición de noble la confiere la institución familiar y la cultura de linaje a ella vinculada. El prestigio social se deriva del desempeño de un conjunto de dignidades públicas que sitúan a los nobles como permanente presencia en el centro mismo del sistema del honor.

También es llamativo comprobar cómo y de qué forma la tratadística nobiliaria lusitana del período y los textos manuscritos referidos a lo nobiliario, no hacen distinción alguna entre nobreza-fidalguia al hablar sobre los rasgos y señas de identidad. António Rodrigues, Rey de Armas de don Manuel I, escribió su Tratado Geral de nobreza hacia $1512^{20}$. En él se habla de nobres, fidalgos, infanzones, y un largo etcétera de situaciones bajo el prisma unificador de la idea de la fama y del prestigio vinculado a todos los hombres honrados. Años después, Álvaro Ferreira de Vera, titula a su texto de 1631, Origem da nobreza civil ${ }^{21}$. João Pinto Ribeiro escribió hacia 1648 su Sobre os títulos da nobreza de Portugal ${ }^{22}$. Manuel Severim de Faria, al hablar de los nobles en sus Noticias de Portugal ${ }^{23}$ de 1644, utiliza el epíteto, nobreza das familias para incluir a todas las categorías nobiliarias en el tercero de sus discursos, incluso comienza sus citas de autoridad con la obra de Scipione Ammirato sobre las familias nobles napolitanas. Antonio Coelho, Rey de Armas de Felipe IV, de D. Juan IV y don Alfonso VI, en su texto, Livro em que se trata da Origem dos Reis e Quantos houve em Portugal e como Sucederam, cuando trata de los distintos grados jerárquicos dentro del sistema del honor, habla directamente de que todos ellos son nobles, en tanto que "suposto que a verdadeyra nobreza seja adquerida por vertude propia" ${ }^{24}$. Esta afirmación, realizada a principios del siglo XVII y que recoge la tradición castellana esbozada por Diego de Valera en su Espejo de la Verdadera nobleza, de $1492^{25}$, también aparece mencionada por el ya citado Álvaro Ferreira de Vera, "suposto que a verdadeira nobreza seja a virtude"26. Lo que termina por demostrar que dentro de la idea de nobleza, el lenguaje para definir lo que es ser noble y no serlo tiene que ver en un primer término con un asunto central, la identificación política de los honrados. Todos cuantos están dentro de la definición de noble, son honrados, privilegiados.

Sea como fuere los honrados, merecedores de permanecer dentro del sistema, debían ser explicados y descritos atendiendo principalmente a sus rasgos identitarios,

\footnotetext{
${ }^{19}$ FARIA, op. cit. (nota 17), f. 81.

${ }^{20}$ RODRIGUES, António: Tratado Geral da Nobreza [1512], ed. Alfonso de Dornelas, Lisboa, 1931,

${ }^{21}$ VERA, Álvaro Ferreira de: Origem da nobreza politica, Mathias Rodríguez, Lisboa, 1631.

${ }^{22}$ RIBEIRO, João Pinto: "Sobre os Títulos da Nobreza de Portugal e seus privilegios", en Obras varias sobre varias casos com três relaçõesde direitto e lustre. Ao Desembargo do Paço Eleyçoens, Perdoens \& pertenças a sua jurisdição compostas pelo Doutor João Pinto Ribeyro, Coimbra, [1729]

${ }^{23}$ FARIA, op. cit. (nota 17)

${ }^{24}$ COELHO, António: Livro em que se trata da Origem dos Reis e Quantos houve em Portugal e como Sucederam, ed. de Manuel Artur Norton, Lisboa, 2006, p. 69.

${ }^{25}$ Esta es la opinión que mantiene Manuel Artur Norton en la introducción al texto. Op.cit ( supra), p. 31.

${ }^{26}$ VERA, Álvaro Ferreira de: Origem da nobreza política, Mathias Rodriguez, Lisboa, 1631, ed. de 2005 , p. 23
} 
y éstos eran una suerte de lugares comunes sobre los que gravitó el debate en torno a lo nobiliario, contienda intelectual y administrativa, de la que no escapaba ninguno de los escalones jerárquicos que componían el estamento privilegiado. Esta polémica generó un discurso en el que se incluían por igual a todos los escalones de la nobleza lusitana.

¿Puede el término nobre resultar un neologismo tanto para la lengua portuguesa como para su legislación? En las propias Ordenações Filipinas de 1604 encontramos que la palabra únicamente aparece indicada una sola vez. Se define nobre, como lo opuesto a peão, dualismo que, por otra parte, también encontramos en Castilla (noble-plebeyo). Según Antonio Manuel Hespanha, la inclusión del término nobre en el ámbito jurídico portugués tendría que ver con la consideración bipolar que existía en el derecho italiano y la recepción de éste en Portugal ${ }^{27}$. Se evidencia de este modo, al igual que en Castilla, la diferencia entre nobles e innobles que encontramos referida en alguno de los principales tratadistas de nobleza luso-castellanos e, igualmente, parece que es con la llegada de los Habsburgo cuando se comienza a designar con frecuencia a todos los que no son plebeus con el epíteto de nobles. Este hecho no resulta en ningún modo baladí, sobre todo si tenemos en cuenta, como dirá ya en 1649 uno de los principales implicados en la rebelión de 1640, João Pinto Ribeiro, que "fidalgo é a palabra e título mais geral com que conhecemos a nobreza"28. Se trataría en este punto de un término que define dos situaciones distintas. La palabra nobreza hace referencia a un universo amplio, en el que estarían incluidos todos aquellos miembros del estamento privilegiado. Sin embargo, y aparentemente, bajo la acepción del término fidalgo, se hace referencia a la categoría jurídica que posee un conjunto de prerrogativas y privilegios. Lo que resulta más importante es que en ambos casos el lenguaje identifica los conceptos de fidalgo y de nobre como dos categorías dentro del sistema del honor, otorgando al primero la singularidad del derecho y al segundo una acepción más sistémica.

Así podemos encontrar que la tratadística nobiliaria portuguesa no hable ni declare en sus títulos palabra alguna sobre la fidalguia. Lo que debe llevarnos a considerar que el término nobreza se extenderá como uso general de definición y distinción del estamento privilegiado y de sus distintos estratos jerárquicos. Hay pues un consenso central en resaltar la idea de fidalguia, recurriendo a la palabra nobre- nobreza, si bien, tal y como indicará ya en 1644 Manuel Severim de Faria "e como os nobres Portugueses estimam, e com razão, tanto sua generosidade e fidalguía, é justo que não falte em nosso vulgar esta materia[...] em que se veja que cousa é nobreza"29. Para asignar a continuación un conjunto de palabras que expresan diferentes categorías e instituciones nobiliarias que glosarían la idea de nobreza-fidalguia: "e as partes consta, e da origen que tiveram os Apelidos, e

${ }^{27}$ HESPANHA, António Manuel: "A nobreza nos Tratados Jurídicos..." en Penélope. Revista de História e Ciências Sociais, no. 12,, 1993, p. 28.

${ }^{28}$ RIBEIRO, João Pinto: "Sobre os Títulos da Nobreza de Portugal e seus privilegios", en Obras varias sobre varias casos com três relações de direitto e lustre. Ao Desembargo do Paço Eleyçoens, Perdoens \& pertenças a sua jurisdição compostas pelo Doutor João Pinto Ribeyro, Coimbra, [1729], 1649, ed. de 1730, Lisboa, p. 122

${ }^{29}$ FARIA , op. cit. (nota 17), p. 81 
Brasões das linhagens nobres, e como se ilustraram com a clareza das dignidades e acçõoes das virtudes" 30 .

Tal y como escribirá en 1631 Álvaro Ferreira de Vera, la nobilitas latina es lo que los portugueses llaman nobreza, y se derivaría del hecho de que era el término para definir a "aqueles que notoriamente eran bons e conhecidos por esses" ${ }^{31}$. Será, en opinión del autor, la nobleza que conceda el soberano la que termine por asociarse con el término fidalguia, dejando claro que esta nobleza, civil o política ${ }^{32}$, se origina en la idea del reconocimiento público de la misma.

Un ejemplo de esto lo constituye el texto del caballero de Calatrava don Fernando Alvia de Castro, que el 18 de diciembre de 1627 daba por concluido un texto que verá la luz pocos meses después bajo el título de Panegírico Genealógico y Moral del Excelentísimo Duque de Barcelos ${ }^{33}$ impreso en Lisboa por Pedro Craesbeeck. El texto pretende relacionar al duque de Barcelos con las casas y familias más reputadas de Castilla, insistiendo en conceder al término noble la categoría de mejor y superior. Utilizando tanto las fuentes clásicas como las contemporáneas es fácil encontrar a Juan Benito Guardiola y su Tratado de nobleza $a^{34}$, llamado en el texto "fray Juan de Guardiola" a Jerónimo de Aponte y su Luzero de la nobleza de España; Bernabé Moreno de Vargas, al que el autor llama "Bartolomé de Vargas". Todos ellos sirven a Castro para ofrecer un panorama del linaje brigantino, único, significando sobre todo su consideración de nobles. La idea de que en el término nobreza se aúnan tanto una categoría política como una institucional, queda resumido en: "gran antigüedad por cierto y estima a sus sucessores, por ser la sangre antigua para la nobleza de mucha importancia, consistiendo la verdadera (según Aristóteles) en mucho de una familia ilustre en hechos y virtud"35. La autoridad del estagirita se ve reforzada por la fuerza normativa que se atribuyen a las Partidas como texto unificador de doctrina nobiliaria en los territorios luso castellanos "allá difinió el Rey don Alfonso el Sabio a la fidalguía, ser nobleça que viene por linaje" ${ }^{36}$, justificando la idea de superioridad y lo meritocrático del término nobleza con la circunstancia de que en la nobleza se juntan: "el valor militar que es el principal para la grandeça de las casas, se haze una nobleça heroica realçada con mercedes y acrecentamientos de los Reyes, porque aunque en rigor para ser fina no depende delllos" ${ }^{\prime 3}$. Faltaría un último pilar para reforzar el argumento de superioridad y la idea de prestigio asociada al término nobreza: "todavía son menester riqueças para sostenerse y obrarla con grandeça y respecto, y sin ellas, mal se hará. Por esto se

\footnotetext{
${ }^{30}$ Ibidem

${ }^{31}$ VERA, op. cit., p. 21.

${ }^{32}$ Ibidem, p. 23.

${ }^{33}$ CASTRO, Fernando Alvia: Panegírico Genealógico y Moral del Excelentísimo Duque de Barcelos, Lisboa, 1628.

${ }^{34}$ GUARDIOLA, Juan Benito: Tratado de nobleza y de los titulos y ditados que oy dia tienen los grandes y claros varones de España, Viuda de Alfonso Gómez, Madrid, 1591.

${ }^{35}$ CASTRO, op. cit., (nota 33), f. 29r-v

${ }^{36}$ Ibidem, f. $29 \mathrm{r}-\mathrm{v}$

${ }^{37}$ Ibidem.
} 
dize que la riqueça es nobleza, pero no nobleza viua, sino por la parte que tiene para hacerse grandes cosas ostentativas" 38 .

Estos hechos son relevantes ya que circunscriben la noción de nobleza dentro de los límites interesados de su tiempo y consiguen, además, que el valor global del término se extienda a todos los grados de la jerarquía nobiliaria lusa, de tal modo que palabras como fidalgo, cavaleiro, nobres, se unifiquen en la exégesis del sistema del honor, al ser éstos los principales detentadores del mismo. Escribía unos años después Manuel Severim de Faria una clara composición de la nobleza portuguesa:

"Há nesste Reino cinco graus de Nobreza, segundo a Ordenação l. 5, t. 139, o primeiro, são os Vassalos, que têm cavalos, e o segundo os escudeiros, o terceiro os cavaleiros, o quarto os fidalgos de cota de armas, e geração, que têm insígnias de nobreza, O quinto é dos fidalgos, que têm assentamentos, e foro na casa del Rei. Entre estes tambén há diferença; porque as leis do Reino fazen menção de três géneros de solares, que são solar conhecido, solar com jurisdição e solar grande. Os de solar conhecido, segundo o Doutor António Francisco, são aqueles que têm a nobreza dos avós e bisavós; de modo que se não pode pôr en dúvida ser o tal apelido nobre, é de fidalguia antiga. Os de solar com jurisdição são os senhores das terras que por doação Real as possuem e governam com suas jurisdições. Os de solar grande são os duques, marqueses, condes, viscondes e barões de título que são verdadeiramente grandes, e por esta causa chama a Ordenação fidalgos de grande solar. Os Reis deste reino fizeram sempre tanto caso da nobreza, que só dela se serviram, assim nos cargos de Estado, como nos da ustiça, fazenda e milícia; e no serviço da casa real, não são admitidos senão só nobres" ${ }^{39}$.

El linaje es convertido en amalgama que refleja no sólo el pasado de una familia, sino su posición en el presente. Justifica los méritos y glorifica las virtudes individuales convirtiendo en argumento de calidad un conjunto de certezas que son consagradas por la corona y recogidas por la opinión pública dentro del discurso sobre la idea de nobleza. En tanto que más que una palabra o palabras, nobre y fidalgo hacen referencia a ideas, a ideas de fama, prestigio y poder dentro de un sistema social que premiaba la desigualdad. Así las palabras del conde de Colares sobre la dimensión temporal de la nobleza cobran un valor esencial como reflejo de una determinada concepción de lo noble: "como todas las familias del mundo, en la realidad dedusen su origen de nuestros primeros padres, unidos a buscar por principios de la noblesa las más antiguas noticias comprobadas por historias"40. Estos hechos terminan sustanciándose en el verdadero catalizador del prestigio social del término nobrefidalgo, la vinculación a la idea de privilegio: "Privilegios y donaciones, bastándoles la antigüedad y continuación de casamientos para ilustrar una familia"4l. Esto terminará por conferir a un linaje, parentela, o familia, la dimensión real de aquello que son y lo que la opinión pública percibe que son mediante el uso de los términos

\footnotetext{
${ }^{38}$ Ibidem, f. $29 \mathrm{r}-\mathrm{v}$

${ }^{39}$ FARIA, op. cit. (nota 17), p. 83

${ }^{40}$ Linajes del conde de Colares, BNE, Ms, 11751, f. 164r.

${ }^{41}$ Linajes del conde de Colares, BNE, Ms, 11751, f. 164r.
} 
adecuados para comunicar y legitimar su posición política/social: "pero en la familia y linaje de los Atayde hallamos un blasón y solar fundado por armas con anterior nobleza de sangre y continuidad"42

En muchos casos en la exégesis de un apellido o de un linaje encontramos referidos términos que podrían parecer incompatibles atendiendo a una composición jerárquica de la nobleza lusitana, pero realmente remiten a un imaginario colectivo construido en torno a la idea de superioridad civil de los miembros de la misma. Así por ejemplo hablando del origen del apellido Atayde y la línea genealógica continuada por varon de los condes de Castanheira, sitúa el origen del apellido en "don Monino, Cavallero Gascón"⿻33 . Cuando se pasa a hablar de otro de los ilustres antepasados, se comienza diciendo", don Monino Henriquez... Rico home de los Reyes Sancho el segundo"44. Continua la exposición de los antepasados, a los que se sigue denominando "ricos omes de Portugal" 45 , "señores de la casa de"46 o nuevamente "cavalleros" ${ }^{\text {" }}$. Será cuando llegue la hora de tratar de don Álvaro González de Atayde, que comience a aparecer la dignidad, "señor de esta casa i primer conde de Autoguía por merced del rey don Alfonso V"48. La sucesión de méritos sobre los que se construyen las calidades de este linaje y las distintas formas de comunicación, manuscritas, impresas, hacen que la circulación de ideas en torno a la consideración de nobrefidalgo de un individuo, adquiera tintes cada vez más "aristocratizantes" en tanto que cualquier individuo terminará por reclamar para él y sus antepasados los epítetos más significativos de la consideración político-civil de la nobleza.

Esas "balsas de sangre" que refería Faria e Sousa en su Epitome invocan al universo siempre cerrado de las jerarquías y de los apellidos y de la en ocasiones conflictiva realidad individual-colectiva. Para Faria e Sousa, la consideración general de privilegiado es la palabra nobre o nobreza. "La nobleza de cada uno todavía se mide por el lugar o fuero que tiene en la casa Real, i entre los más aventajados es gran ventaja en la honra tener más un real en la moradia"49. Vincula la idea de prestigio del término fidalgo con los elementos básicos de la identidad nobiliaria: "fue costumbre que sabido en pallacio que avia nacido hijo a algún fidalgo, luego un criado del Rei iva a su casa con la provisión o cédula Real del fuero, ò moradia que dexava al niño en los pechos de su madre" ${ }^{50}$. La circunstancia vincula la herencia con el reconocimiento al recién nacido de su condición de honrado. Esta honra, además de vincular al bebé con la nobleza de sus ancestros, tenía su paralelo en la consideración que se hacía a los apellidos. Se trata de una búsqueda racional de la nobleza del reino de Portugal, ya que como indica Faria e Sousa, desde el conde Don Pedro, varios han
${ }^{42}$ Ibidem.
${ }^{43}$ Ibidem, f. 168r.
${ }^{44}$ Ibidem, f. 170r.
${ }^{45}$ Ibidem, f. 172r.
${ }^{46}$ Ibidem, f. 172v.
${ }^{47}$ Ibidem.
${ }^{48}$ Ibidem, f. 173 r.
${ }^{49}$ SOUSA, Manuel de Faria: Epitome de historias Portuguesas, Lisboa, 1640, p. 668.
${ }^{50}$ Ibidem. 
sido los que han tratado sobre las familias nobles del reino. Sobre todo António de Lima y la obra del rey don Manuel, quien impuso la creación del Livro da nobreza ${ }^{51}$, circunstancia bastante especial esta de recopilación de toda la nobleza del reino y sus blasones o marcas de "prestigio". Este hecho ayuda como ningún otro a configurar en torno a la idea de nobleza y sus poseedores un halo de exclusividad. El propio Faria e Sousa, cuando trata sobre alguno de los apellidos de la nobleza, citando la obra de don Antonio de Lima, comienza indicando que, "las familias que oi verdaderamente gozan esplendor de nobleza" 52 , término que se debe sumar a todas las marcas de prestigio que se singularizan en el vocablo noble y que tienen su significación dentro del sistema del honor. Así, a los Almada los sitúa como descendientes de "cavalleros ingleses" $53 \mathrm{y}$, siguiendo con la lógica argumental en torno a la nobleza, los vincula con un hecho de armas para continuar afirmando que, "tuvieron título" 54 . Para los Almeidas, además de indicar que tenían tres o cuatro títulos, sitúa su origen en las tierras del Miño, dónde

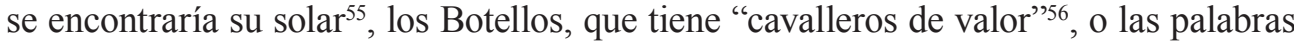
que dedica a los Moura: "en don Pedro Rovi, porque ganó valerosamente la villa de Moura en tiempo de nuestro primero Rei i desde entonces tiene de padrea a hijos la sucesión continuada" 57 . Todos ellos son elogios a un pasado que justifica la grandeza del presente de los todopoderosos Moura. A esto hay que añadir, " tuvo varones claros en la paz i en la guerra i tiene títulos" 58 , lo que nos debe hacer entender que, además de estar integrados perfectamente dentro del sistema del honor en el Portugal Habsburgo y posteriormente a 1640, en la monarquía española eran sinónimo vivo de verdadera nobleza y esta era su estrategia de legitimación pública ${ }^{59}$.

Pero estas marcas indiscutibles de prestigio afectaban por igual a todos los estratos de la pirámide nobiliaria. Así encontramos en los fidalgos de cota de armas cómo, pese a ser considerados un grupo de rango inferior a los titulados, sus signos identitarios son los mismos que los titulados, etcétera, pues en muchos casos son miembros de las mismas familias. Si tomamos como ejemplos algunos de los certificados de armas concedidos a los fidalgos encontraremos en ellos una serie de elementos básicos que, más allá de ser requisitos $a d$ hoc, eran verdaderos espacios de definición y distinción frente a aquellos que no podían argumentar estas calidades. De este modo el trasfondo de excelencia y fama que encierra la idea de nobleza en Portugal se centraba en la legitimidad, la limpieza de sangre, la nobleza de los antepasados:

${ }^{51}$ Ibidem, p. 669.

${ }^{52}$ Ibidem, p. 672.

${ }^{53}$ Ibidem.

${ }^{54}$ Ibidem.

${ }^{55}$ Ibidem. La expresión solar puede hacer referencia a la idea castellana del mismo, y el hecho de que el texto esté escrito en lengua castellana reforzaría la idea de que ciertos linajes poseían, además, riquezas.

${ }^{56}$ Ibidem, p. 673.

${ }^{57}$ Ibidem, p. 676.

${ }^{58}$ SOUSA, Manuel de Faria: Epítome de historias Portuguesas, Lisboa, 1640, p. 676

${ }^{59}$ MARTÍNEZ HERNÁNDEZ, Santiago, «Fineza, lealtad y zelo». Estrategias de legitimación y ascenso de la nobleza lusitana en la Monarquía Hispánica: Los Marqueses de Castelo Rodrigo" (1582-1675) en RIVERO, Manuel (coord.) Nobleza hispana-nobleza Cristiana, Madrid, 2009, pp. 913-960, vol. II. 
"Andre Feyo de Castelbranco fidalgo e Prior de São Silvestre de Covilha me pedia e requereu que por quanto elle descendia por linha direita e sem bastardia" 60 , para proseguir indicando que estos fidalgos eran: "das generações e linhagems dos Ribeiros, Feyos e Castelos Brancos que neste reyno são fidalgos de cota de armas e solar conhecido, como consta do testemunho e mais papéis". ${ }^{1}$

Podemos considerar que el asunto del vocabulario sobre la nobleza durante la Edad Moderna acabó convertido en una "verdadera razón de estado" no sólo por el hecho de que la presencia de lo nobiliario y del debate sobre la nobleza se extendiera por todos los rincones, desde las planchas de las imprentas hasta las tintas de las plumas y las covachuelas de los Alcázares y tribunales regios, sino sobre todo porque trataban del estado de las cosas y de las personas y sus umbrales políticos. Probablemente tengamos que acordar con Fernando Alvia de Castro en su La verdadera razón de $E_{\text {stado }}{ }^{62}$, cuando afirmaba que "es la materia de estado un profundísimo mar, en que ni ay arte que la comprehenda, ni ciencia que enseñe" ${ }^{63}$, expresión que bien podría aplicarse a la nobleza y al vocabulario que la define durante la Edad Moderna.

La base sobre la que se construyó la memoria de los linajes en Portugal estaba relacionada con la justificación de la desigualdad entre los hombres. Así partiendo del viejo axioma de Jerónimo Carranza "cada qual se contente con su officio" ${ }^{64}$ y del esbozado por Ferreira de Vera en la clásica idea de la mortalidad de los individuos: " $A$ nobreza dos homnes é coisa mortal e caduca" 65 . El hecho de que la condición de noble esté relacionada directamente con la posesión de determinadas virtudes se significa en la exégesis que la literatura doctrinal sobre la nobleza realizó. Autores como el ya citado Ferreira de Vera, presentan al noble como un individuo coronado por una serie de virtudes que legitiman su posición política y su función social, confiriendo al término noble de un significado determinado. Además del ya mencionado respeto a la memoria de sus pasados y a la obligación a repetir los hechos de éstos, el verdadero noble, en opinión de Ferreira de Vera, debía tener una actitud tendente a la búsqueda de la gloria, en tanto que la recuperación de la memoria nobiliaria sitúa a los individuos en su verdadero espacio político en el presente:

"Les convén ser bons e virtuosos, afáveis e comedidos, que então corresponde ao nome que têm de conhecidos por bons [...] tambén é coisa conveniente aos nobres serem prudentes[...] e o mesmo digo da liberalidade, porque é uma virtude propia

${ }^{60}$ Nos referimos al Blasón de Armas realizado por Jerónimo de Matos, en GODINHO, António: Livro da nobreza e perfeição das armas, ed. de ALBURQUERQUE, Martim de, y LIMA, João Paulo Abreu, Lisboa, 1997, p. 39.

${ }^{61}$ Ibidem

${ }^{62}$ CASTRO, Fernando Alvia: Verdadera razón de Estado, Lisboa, Pedro Craesbeeck, 1616.

${ }^{63}$ Ibidem f. 3v.

${ }^{64}$ CARRANZA, Jerónimo: Libro de Hieronimo de Carrança, natural de Sevilla, que trata de la philosophia de las armas y de su destreza y de la agresión y defensión christiana, Sanlúcar de Barrameda, 1582, f. XVIIv.

${ }^{65}$ VERA, op. cit. (nota 21), p. 78 
de ânimos generosos. A qual faz aos nobres tão conhecidos pelo que dão como pelo que governam". ${ }^{6}$

Cuando Felipe II llegó a Tomar para ser jurado como rey de Portugal, en el Convento de la ciudad se encontraban representados jerárquicamente todos y cada uno de los linajes lusitanos comunicando, por encima de las cuestiones estrictamente cortesanas, en primer lugar su calidad biológica, en segundo lugar su poder político y finalmente su fuerza simbólica. Leyendo la narración que se hizo sobre el juramento de Felipe II podemos ver este hecho:

"16 de abril siendo sitio muy apropósito para ello donde todos tuvieron sus lugares muy cumplidamente y el pueblo lo pudo ver sin apretura ni ruydo[...] salió su Magestad acompañado de todos y vestido con una sotana de tela de oro[...] ]el duque de Bragança yva delante de Su Magestad con el estoque y descaperizado. El duque de Barcelos su hijo, allí con él, y don José de Meneses, alferez mayor con el estandarte real. Llevava el rey de armas y maceros". ${ }^{67}$

Además de éstos, se encontraban allí, "a la mano izquierda" el Marqués de Villareal y su hijo ${ }^{68}$, el conde de Castanheira, el de Portalegre, el de Matosinhos, el de Linhares junto al de Vidigueira y el Barón de Alvito ${ }^{69}$. Igualmente se encontraban allí representados los "fidalgos y señores de vasallos" ", familias todas que podemos ver en los textos doctrinales sobre nobleza publicados en el Portugal previo a la llegada de Felipe II y en los años inmediatamente posteriores.

El propio Ferreira de Vera habla ya de que los primeros duques de Portugal fueron:

"Os infantes d. Afonso, D. Henrique e d. Pedro; um de Bragança, outro de Coimbra e oitro de Viseu, todos filhos del Rei D. João I[...] do Primeiro, se continuaram sucesivamente os mais Duques até o presente duque, don João, que conserva sua dignidade, que é de maior estima, tanto por ser descendente de muitos reis, quanto por ser o mais antigo duque de Portugal, Castela e Italia". ${ }^{71}$

No cabe ninguna duda que, a los ojos del teórico, el peso en la comunicación de la condición de noble lo lleva el binomio sangre-servicio y, manteniendo un esquema aristotélico-tomista, sitúa la posibilidad de nuevos ennoblecimientos en la capacidad para hacer cosas dignas de honor, sin olvidar en su exégesis que estos actos deben ser requeridos $a d$ hoc a todos los que deseen ennoblecerse limitando,

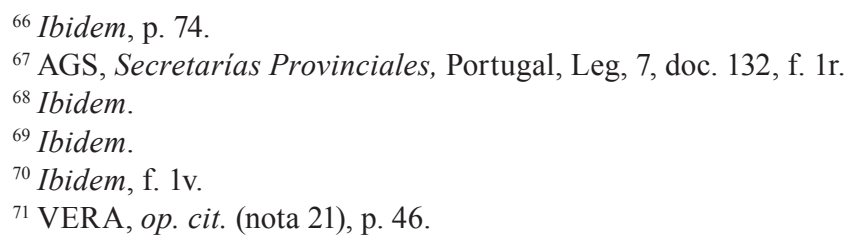


al menos teóricamente, el peso de la idea del linaje como única justificación para obtener la calidad de noble. Sigue en este punto los lugares comunes de la teoría nobiliaria medieval que ya planteara Bártolo de Sassoferrato y que fueron recibidos en la Península en las obras de Diego de Valera y Fernán Mexía entre otros y que gozaron de una gran recepción entre los teóricos nobiliarios portugueses.

La materia central que se aborda en la noción de nobreza es la del privilegio. La idea de privilegio es la base sobre la que se sustenta la doctrina nobiliaria tanto en el Portugal Habsburgo como en el resto de territorios de la Monarquía. Ya en las Cortes de Tomar se trató del asunto de los privilegios propios de la nobleza portuguesa. Éstos trataron de ser defendidos por los nobles en las Cortes de Tomar mediante la Patente das Mercês, Graças, privilégios de que el Rei D. Filipe noso señor fez Mercê. Así el día 16 de abril del 1581 el monarca castellano se reunió con una representación de las figuras mayores de la nobleza lusa y las altas dignidades eclesiásticas. Felipe II prometió guardar los privilegios nobiliarios. Se trataba, por parte de la nobleza portuguesa, de mantener ciertos canales de promoción social tradicionales dentro de su sociedad junto con el cultivo de una nobleza provincial que mantenía sus preeminencias en determinadas zonas y que fue muy bien visto por el propio Felipe II, lo que terminaba por conferir al término noble/nobleza y allegados, un valor determinante en la constitución del poder. El vocabulario sobre la nobleza hacía alusión a una clasificación social de los individuos y a su naturaleza jurídica, pues como afirmaba el profesor Hespanha, "o carácter jurídico destas classificações tem ainda importancia num outro plano: o seja, enquanto atribui competências privativas a certos actores sociais para gerirem as taxinomias"72. Así pues el vocabulario nobiliario hace referencia tanto a una aproximación taxonómica como a una concepción legal. No es fácil conocer cuándo se comenzó a utilizar el vocablo nobre en el mundo luso y tampoco son muchos los trabajos que sobre el particular se han realizado, pero coincidimos con el profesor Nuno Monteiro cuando afirma que sería interesante realizar un estudio sobre la aparición del término y su presencia y evolución a lo largo de la Edad Moderna ${ }^{73}$. A esto debemos añadir las políticas que los diferentes monarcas portugueses mantuvieron hacia la nobleza a lo largo de los siglos XVII y XVIII y que, entre otras circunstancias, estaban encaminadas a reducir el papel y privilegios de la nobleza ${ }^{74}$, si bien esto no influyó decisivamente en la noción y reputación que el término nobre tuvo, al menos en el nivel de los textos doctrinales y en los normativos.

${ }^{72}$ HESPANHA, op. cit. (nota 27), p. 28.

${ }^{73}$ MONTEIRO, Nuno, "Poder Senhorial. Estatuto nobiliárquico e aristocracia" en MATTOSO, José (dir.), História de Portugal, o Antigo Regime, Lisboa, 1997, p. 298

${ }^{74}$ Ibidem 
Una serie de marcas, derivadas de la necesidad de vivir a "lei de nobreza" constituyen como rasgos esenciales para ofrecer una visión posibilista de la idea de nobleza tanto en el Portugal de los Avis como en el de la tercera dinastía. Se trata por lo general de resaltar la significación de los valores nobiliarios mediante la exégesis de éstos realizada tanto por nobilistas como por la propia administración, convertidos ambos en agentes de los tópicos constitutivos del sistema del honor en el Portugal habsbúrgico; identidad basada por igual en la tradición biológica y en la consideración social de sus méritos y finalmente en una sutil capacidad de ascenso en la jerarquía nobiliaria lusitana.

Las Ordenações filipinas establecerán una interpretación de la idea de nobleza centrada tanto en criterios biológicos como políticos. Esto permitió, desde un primer momento, adecuar los discursos nobiliarios castellano y portugués, incluso en las negociaciones previas a 1580 . De un lado se ratificaba la existencia de una nobleza de la sangre anterior a los Habsburgo y que estaba certificada por el tradicional ordenamiento jurídico portugués. De otro se mantenía una estructura social que permitiese cierta permeabilidad hacia el estamento privilegiado, posibilitando el acceso al sistema del honor de todos aquellos que apoyaron la causa filipina, integrando de este modo tanto a la vieja nobleza de sangre como a elementos recientemente arribados. En líneas generales, se trataba de una taxonomía glosada por los nobilistas que abarcaba todas las actitudes políticas relacionadas con la idea de sangre y de servicio.

Nobre, pues, es aquel que desciende de un linaje concreto y que mediante la transmisión sanguínea de algunos valores está capacitado para gozar de ciertos privilegios dentro de la sociedad. Al noble le están conferidos ciertos símbolos de su posición social y de su poder político sobre los que también se legisla. Por ejemplo, las mismas Ordenações filipinas, hablan en el apartado V sobre los blasones como símbolo de nobleza. En esta acepción se engloban todas las situaciones de privilegio que se daban en el Portugal de los Avis, en el Habsburgo y en el de los Braganza. Así, la palabra nobreza representaba la señal de identidad para todos los privilegiados e integrantes del sistema del honor.

El término nobre es, pues, una categoría jurídica y una tipología social que, dentro del imaginario colectivo y nobiliario, poseía una serie de prerrogativas propias que le conferían una capacidad no sólo política si no también simbólica. Los nobles eran las personas vinculadas al privilegio; es un "arquiconceito que agrupa todas as pessoas honradas, ou seja todas as pessoas distinguidas por um qualquer dos antigos estados da nobreza"76. Es, también, un concepto resistente al tiempo, y podría explicar perfectamente una estructura de larga duración que se reforzaba con las controversias que surgían y que contribuían a aumentar sus cualidades excepcionales dentro del orden social del Portugal del Quinientos y Seiscientos.

${ }^{75}$ Este término aparece referido por ejemplo en las habilitações para el acceso a las Órdenes Militares de Cristo, Avis y Santiago en Portugal y ha sido tratado por OLIVAL, Fernanda, Para uma análise sociológica das Ordens Militares no Portugal do Antigo Regime (1581-1621), Tesis de Mestrado. Lisboa, 1988.

${ }^{76}$ HESPANHA, op cit. (nota 27), p. 30. 
En la sociedad portuguesa del periodo filipino, la simple consideración de un individuo como noble le situaba en primer lugar lejos de su contrario, peão. No se entraba, en este punto, en considerar su jerarquía dentro de la nobleza, pues no se trataba de definir ningún estado singular de la misma. Servía únicamente tener claro las particularidades propias de los nobles y su clasificación política en la sociedad ${ }^{77}$.

De este modo, los juristas construyeron en torno a la palabra nobleza un arquetipo basado en su origen, en sus privilegios, en sus símbolos y en su poder político dentro de la sociedad. El nobilista y jurista portugués Jerónimo Osório, afirmaba que la nobleza movía a un sentimiento de veneración hacia ella ${ }^{78}$. La opinión de las personas sobre la nobreza, que es percibida como calidad de un individuo, venía a ser un escrutinio demasiado fuerte en la sociedad portuguesa, generando una opinión pública en torno al concepto noble que bien superaba los límites de las categorías jurídicas. Asumir por parte de la sociedad la posición de la nobleza, sus funciones y categorías y, por qué no, sus valores, representaba un horizonte demasiado ambiguo para buena parte de la sociedad lusa. Bien es cierto que, entorno a la palabra noble, se intentó hacer, por parte de los miembros del estamento privilegiado, una "pedagogía", explicando así cuestiones básicas como la genealogía, la heráldica, el linaje. Igualmente términos como la virtud, el honor, la magnanimidad eran glosados y explicados desde todos los puntos de vista ${ }^{79}$ y no únicamente como simples cuestiones epidérmicas al estatuto de noble. Se trataba de singularizar en el noble o en la nobleza la posesión de una vasta amalgama de valores. Es esta una cuestión que afectaba por igual a ambos reinos peninsulares y sobre la que queda mucho que decir. En estas líneas ofrecemos una primera aproximación a este asunto.

Hay, pues, un modelo explicativo de la sociedad en torno a las palabras nobre, nobreza e fidalgo, lo que supone que, en 1581 y en los años sucesivos, la legitimación de la posición social de la nobleza frente a la nueva dinastía se hará en función de unos parámetros conocidos por toda la sociedad y representados en el respeto a una tradición legislativa ya existente y en la adecuación de la concepción de nobleza castellana que tomamos aquí de la obra del castellano Rades de Andrada:

"[Nobleza es] aquella que se adquiere por herencia de padre y abuelo en cuanto a las preeminencias, o por estudios y grados en buenas ciencias, o por títulos y dignidades de emperadores, reyes, príncipes, duques, ricoshombres, condes, marqueses, barones,

${ }^{77}$ En Castilla también existía una polarización de la sociedad en torno al binomio NOBLE-PECHERO que articulaba la definición de los espacios políticos, jurídicos, económicos y culturales de la sociedad.

${ }^{78}$ Hemos trabajado con la traducción al portugués. Ver OSÓRIO, Jerónimo: Tratados da nobreza civil e cristã, Lisboa, 1542, ed y trad. de Guimarães Pinto, António, Lisboa, 1996, p. 87.

${ }^{79}$ Nobre e fidalgos tenían que mantener un comportamiento adecuado a su posición, si bien algunos autores hablan abiertamente de que el fidalgo no tenía que cuidarse al ser ésta una categoría adquirida por linaje. La realidad, pensamos, va más allá, pues la percepción social de unos y otros quizá no estuviera tan compartimentada como en ocasiones podemos llegar a pensar y, quizá, la simple consideración de un individuo como nobre sirviera para delimitar su conducta ideal dentro de la sociedad. Sobre esta diferenciación véase la obra de MAGALHÃES, Joaquim Romero: "A sociedade" en MATOSSO, José (dir), História de Portugal, No Alvorecer da Modernidade (1480-1620). Vol. III, p. 490. 
almirantes y otros que hay en cada tierra o por servicios muy notables hechos a emperadores, reyes y otros príncipes que pueden dar nobleza civil y política" ${ }^{80}$.

Es esta consideración de Rades un lugar común dentro de los nobilistas del Quinientos ibérico. Lo que sí queremos hacer notar es que la definición de nobleza aquí recogida y la expresada en las fuentes del derecho común para el ámbito portugués sirven para ratificar una definición de la palabra que deriva en un acto real, esto es, vivir como un noble y ejercer las funciones propias de un noble. La palabra nobleza hacía pues alusión a un mundo exterior y a un mundo interior que, regido por las leyes del hombre y las de la naturaleza, acaba por primar la idea de reputación social como forma de acceso a la nobleza y convierte el discurso jurídico en un espejo de los sistemas sociales de distinción social ${ }^{81}$.

En tanto que una de las excelencias de la monarquía portuguesa era su nobleza, António de Sousa de Macedo escribió en 1631 su Flores de España y excelencias de Portugal. El texto, publicado en Lisboa por Jorge Rodríguez el año de 1631, recoge en el capítulo VII una interesante reflexión general sobre la definición de nobleza. Se trata de una explicación general sobre el estamento apoyada en la autoridad del Aristóteles de la Politica, Juvenal y sus Sátiras, Bartolomé Chassaneau y su Cathálogo de Gloria Mundi, Tiraqueau. Estos autores sirven a António de Sousa, "moço fidalgo y caballero del hábito de Cristo", para articular un discurso sobre la idea de nobleza construido en torno a la idea de virtud. Pero, más allá de esta generalidad propia de las excelencias del reino de Portugal, la exégesis que el moço fidalgo realiza sobre la nobleza en Portugal sirve para enmarcar al término noble dentro de los parámetros de la antigüedad pues la hace derivar de $\operatorname{los} \operatorname{Godos}^{82}$, alegando a la autoridad del castellano Gregorio López Madera. En tanto que antigua, esta nobleza terminará por extenderse a las familias. Aumentando la calidad de la nobleza basada en el tiempo ${ }^{83}$, también legitima los evidentes procesos de ennoblecimiento que precisan de una legitimación en el tiempo. La palabra nobre representa un concepto cerrado, un todo organizado que, en su exposición pública, termina por representar lo que se es, lo que se fue y lo que se será ${ }^{84}$. Esto permite al autor, al llegar a la VI de las excelencias de la nobleza de Portugal, hablar de los fidalgos. Más allá de entrar en disquisiciones sobre la consideración judicial de la categoría de fidalgo, el autor comienza por indicar que esta categoría deriva del hecho sustancial de que la nobleza es antigua: "finalmente tienese tanto la mira en Portugal en la nobleza antigua" tanto que esta antigüedad es una indiscutible marca del prestigio social de la nobleza:

\footnotetext{
${ }^{80}$ RADES DE ANDRADA, Francisco: Que cosa sea nobleza, Manuscrito, hacia finales siglo XVI. BNE, Mss. 8631, fol. 91-97v.

${ }^{81}$ HESPANHA, op. cit. (nota 27), p 34.

${ }^{82}$ MACEDO, António de Sousa: Flores de España y excelencias de Portugal, Lisboa, Jorge Rodríguez, 1631, f. 48v.

${ }^{83}$ Ibidem, f. 49v.

${ }^{84}$ Ibidem, f. 50r. Excelencia V.

${ }^{85}$ Ibidem, f. $54 \mathrm{r}$.
} 
"que para unos y otros ser conocidos por quieres son" ${ }^{86}$. Ello obligó a establecer una forma de reconocimiento y conocimiento de las calidades de los privilegiados: "ay [en Portugal] libros del Rey en que están escritos los hombres por sus nombres con títulos y fueros conforme su calidad" ${ }^{87}$. Más allá de las identificaciones que se hacen con la nobleza castellana: "otros con fuero de fidalgos, que es mucho mas, y son los que en Castilla dizen Cavalleros" $" 88$, en Castilla el máximo prestigio social lo tenían los Hidalgos a Fuero de España, que era la condición que se debía acreditar en cualquier probanza de nobleza ${ }^{89}$. Pero tanto el término nobre como el término fidalgo remiten a algo más que realidades fácticas, son categorías sociales y mentales.

La propia definición y categorización del vocablo nobreza y fidalguía, indica cuáles eran a la altura de 1581 los espacios de socialización que éstas mantenían, sus niveles descriptivos, el término y su alusión a un elevado número de valores estamentales y a la diferenciación de los mismos. Todos aquellos elegidos y merecedores de una recompensa estamental se mantenían a la espera del favor regio, mientras que aquellos que ya gozaban del mismo, pretendían escudarse en sus posiciones y mantener su statu quo de cariz biológico. Así pues, bajo la aceptación del término nobre o fidalgo como cúspide de la pirámide social en el Portugal de los felipes, la valoración social de los vocablos era semejante fuera cual fuera el tipo de nobleza del que se tratara pues, como hemos indicado, el "arquetipo fidalgo" concretizaba, resumía y delimitaba las calidades de la nobleza y dotaba al sujeto de una clara diferencia social y jurídica respecto del conjunto de la sociedad. Ello fue posible, al igual que en Castilla, gracias a la acción de autores como Jerónimo Osório, Álvaro Ferreira y un buen número de autores, genealogistas, propagandistas que trabajaron en torno al poder.

En un dictamen del Consejo de Portugal de 1620 Mota Valladares, caballero de la orden de Cristo y miembro del citado Consejo, se expresaba en estos términos sobre la nobleza portuguesa y la asimilación de algunas categorías jerárquicas con las castellanas:

"Y quando uno en Portugal es noble de sangre es tan capaz de todas las cosas de la nobleza como lo son los hijosdalgo de Castilla. Porque aunque uno sea hidalgo no dexa por esso de ser noble, como en Castilla aunque uno no sea caballero, no dexa por esso de se hijodalgo, y assi si los testigos dicen que uno es noble y bive a lei de nobleza es prueba en todo rigor bastante para los hábitos de las Órdenes Militares según los fueros de Espanha"90.

${ }^{86}$ Ibidem.

${ }^{87}$ Ibidem.

${ }^{88}$ Ibidem, f. 54v.

${ }^{89}$ Ver GUILLÉN BERRENDERO, José Antonio: Los mecanismos del honor en Castilla y Portugal, 1556-1621, Tesis doctoral inédita, Madrid, Universidad Complutense, 2008. y POSTIGO CASTELLANOS, Elena: Honor y privilegio. El Consejo de las Órdenes... Soria, 1988,

${ }^{90}$ Consultas y cartas, Manuscrito del siglo XVII. BNE, Ms. 6750, fol. 63r. 
La identificación entre la concepción castellana de noble y la portuguesa parecía chocar en algunos aspectos y provocaría un lógico conflicto sobre la consideración de determinados individuos dentro de la nobleza pues, si bien como hemos dicho, la simple consideración de uno como noble le confería rápidamente un status social diferente, esta circunstancia cambiaba cuando se trata de acceder al estamento, sobre todo en estos momentos en que en Castilla se está operando una oclusión estamental amparada, entre otras cosas, por los Estatutos de Limpieza de Sangre que, prácticamente desde 1570 , aparecen como requisito inexcusable para adquirir nobleza.

Las diferentes consideraciones que la nobleza castellana y la portuguesa tenían en cuanto a su jerarquía no parecían ser un problema para que ni la política de mercedes anteriormente citada de los monarcas castellanos siguiera su curso, ni que se interrumpiese la inclusión de fidalgos en el aparato burocrático de la monarquía en Madrid ${ }^{91}$.

Sea como fuere la nobleza portuguesa, ante la llegada de Felipe II, buscó la manera de conseguir del nuevo monarca tanto mercedes como el mantenimiento de sus privilegios y beneficios, a fin de que la palabra nobleza no se viera afectada, como así ocurrió por nuevas consideraciones llegadas del otrora enemigo castellano. Fernando Bouza sostenía en su tesis que "la defensa de lo que ellos mismos llaman la honra de nobleza parece quedar circunscrita, sin embargo, a los capítulos que corporativamente presentan al nuevo rey las Cortes de abril de 1581 mediante estos, los nobles - continua el autor- querrán velar por el mantenimiento del principio estamental de diferenciación social, que es la garantía última de sus prerrogativas y que exige la exclusión de los otros del disfrute de sus privilegios" 92 , lo cual quiere decir que, pese a la diferenciación taxonómica y conceptual entre la palabra nobleza castellana y nobreza, en Portugal la acción de ambas se mantenía en los parámetros de su espacio político y pretendía en todo momento mantener los elementos básicos de su identidad, aspecto todos ellos recogidos en el término noble.

El vocabulario y el orden en el discurso son realidades propias de todas las sociedades, los conceptos aluden a realidades políticas, sociales y económicas, sobre todo en el caso del término nobleza. La tradición jurídica lusa inscribe a la nobleza dentro de los parámetros y lugares comunes del universo católico y tiene como principio constitutivo los textos legislativos y normativos medievales. En las Ordenações afonsinas podemos encontrarnos con la siguiente definición de nobreza:

"Ca bem assi como a linhagem se nom pode comprar, outro si a honra, que veem per nobreza, nom a podde pessoa haver, se ela nom for tal que mereça por linaghem, ou por uso, ou bondade alguma que haja em si" ${ }^{\prime \prime 3}$.

${ }^{91}$ En su clásica Historia de Portugal, Veríssimo Serrão afirma que, en el año de 1613, el número de hidalgos portugueses en Madrid era superior al del resto de provincias de la monarquía. Ver SERRÃO SERRÃO, Joaquim Veríssimo: História de Portugal, Governo dos reis Espanhóis. v. IV, Lisboa, 1978, p. 309

${ }^{92}$ BOUZA, Fernando, Portugal en la Monarquía Hispánica (1589-1640): Felipe II, Tomar y la génesis del Portugal católico, Tesis doctoral, Universidad Complutense Madrid, 1987, p. 495.

${ }^{93}$ Ordenações Afonsinas, Libro I, tit 63. 
La idea que subyace a toda la exégesis pública del vocabulario en torno a la nobleza es doble. De un lado sirve para enmarcar el debate sobre el poder durante la Edad Moderna y de otro delimitar los espacios del prestigio social que poseían todos aquellos grupos o individuos privilegiados. El objetivo final de todo este entramado intelectual-político es consagrar, en torno al concepto de noble y nobleza, una serie de atributos simbólicos, políticos y culturales que sustancien la idea de excelencia atribuida a la nobleza portuguesa en su contexto continental. En Portugal existe, desde la Edad Media, una literatura nobiliaria caudalosa y un conjunto de prácticas administrativas entorno a la gestión del honor que son la expresión de una realidad conflictiva y de una competencia social en la que el honor, el servicio a un mismo rey, el triunfo personal y el prestigio familiar estaban vinculados estrechamente entre sí en la configuración de la idea de nobleza. Las discrepancias que la historiografía percibe a la hora de analizar el vocabulario sobre la nobleza en el Portugal filipino, o la asimilación de las realidades castellana y portuguesa en la cuestión de sus noblezas que se puede ver en las probanzas de noblezas realizadas a portugueses en Castilla, más allá de resaltar diferencias de matiz, se insertan dentro de un único y singular discurso social sobre la excelencia, el honor, la herencia y el servicio como marcas indiscutibles de proyección personal y de servicio al Monarca y al reino.

Cuando en 1588 Felipe II concedía a don Duarte, hermano del duque de Braganza, la merced de las villas de Frechilla, Villumbrales y un título ${ }^{94}$, sancionaba de esta forma no solamente los servicios directos de los Braganza sino que confirmaba y legitimaba todos los servicios pasados de éstos. El asunto consistía en premiar con unas villas y un título los servicios prestados por la casa y debía de tratarse de lugares adecuados a la dignidad de los Braganza: "Y en el dicho memorial se dice por parte de la señora doña Catalina que la merced que Vuestra Magestad hizo al dicho don Duarte fu de un buen lugar en Castilla, de mil vecinos poco más o menos y quatro mil ducados de renta y título de marqués" ${ }^{\prime 5}$. Esta circunstancia provocó el envío de un memorial, por parte de la duquesa doña Catalina con fecha de 14 de abril de 1592, en el que insistía en resolver algunos detalles derivados de los distintos usos portugueses y castellanos. En lo que aquí nos interesa solicitaba la duquesa que: "el título de marques se le da de por vida, diciendo no ser estilo en Castilla, darse los títulos sino personales y que la costumbre los tiene hechos perpetuos y que por que en este caso ay diferente razón por haversele ofrecido de juro por palabras expresas como esta dicho, suplica a Vuestra Magestad mande que [...] se enmienden [...]"'96, consiguiendo la rápida respuesta por parte de la Cámara de Castilla: " hágase como parece lo de la perpetuidad del título" ${ }^{27}$, y la respuesta del soberano, "pues yo no estoy obligado a mas" memorial en el que decía que:

\footnotetext{
${ }^{94}$ AHN, Consejos, leg. 9034, $\mathrm{n}^{\circ} 1$.

${ }^{95}$ AHN, Consejos, leg. 9034, no 1, s/f.

${ }^{96}$ Ibidem.

${ }^{97}$ Ibidem.

${ }^{98}$ Ibidem.
} 
"El rey nuestro señor, en vida del duque de bargança, don João, que deo tem, me mandou que de su parte lhe disese que considerando o muy conjunto dividido que a senhora dona Caterina tinha con sua magestad e avendo respeyto ao muyto amor que sua magestade lhe tinha a ao que o duque mostrara nas cousas de serviço de sua magestade, depois que entrara nestes seus reynos a a grande confiança que tinha dele e todos seus descendentes procederao da mesma maneyra el he como hicerem a servirem sempre todas as merces que lhe fizesse" ${ }^{\text {"99. }}$.

El propio Felipe II, en la cédula de concesión del título hace constar la bondad y fidelidad de los Braganza:

"Don Phelipe, acatando los muchos y grandes servicios que el muy ínclyto don Juan,
Duque de Bragança, ya difunto, my muy caro y amado primo me hizo durante su
vida y especialmente al tiempo que por fallecimiento del señor Rey de Portugal, don
Enrique, mi tío, que este en gloria sucedí en los mis reynos de aquella corona y fui
personalmente a ellos y el mucho deudo que conmigo tiene doña catalina, duquesa
de Bragança, su mujer mi muy chara y muy amada prima y en alguna muestra de la
voluntad que tengo de honrar y hacer merced a sus hijos y descendientes y entendiendo
que todos ellos procederán de la misma manera y reconocerán siempre las mercedes
que de mi recibierem, tuve por bien hacer merced a don Duarte, hijo segundo de los
dichos duque y duquesa de Bragança de mil vasallos poco mas o menos en estos
mis reynos de Castilla con cuatro mil cruzados de renta[...] y mandamos que hagan
guardar todas las honras, gracias, mercedes y preeminencias, ceremonias y otras
cosas que por razón de ser marques debe haver y gozar y le deven ser guardadas"100

Confirmando la idea de perfectos servidores, Felipe II le concede también un número de vasallos atendiendo en primer lugar a la liberalidad regia: " por quanto de los reyes y príncipes es propio honrar y sublimar y hazer gracias y mercedes a sus súbditos y naturales, especialmente a aquellos que bien y lealmente les sirven"101.

La antigüedad y la generosidad de la sangre Noroña deriva de la Casa Real castellana y portuguesa ${ }^{102}$ y en ningún momento se ha puesto en peligro la pureza y la sucesión de la casa mediante matrimonios más o menos lustrosos ${ }^{103}$. Relacionado con esto, la familia Noronha ha visto cómo por la calidad y cantidad de sus servicios, se ha significado en la colaboración con el proyecto de la monarquía ${ }^{104}$

La idea de que el vocabulario encierra un evidente gusto por el elogio y tiende, en el caso de lo nobiliario, a unificar bajo la idea de excelencia a todos sus miembros, se

${ }^{99}$ Carta de Miguel de Mora, Lisboa, 27 de Julio de 1583, AHN, Consejos, leg. 9034. Ver también BOUZA, Fernando: "En la corte y la aldea. D. Duarte de Bragança. Libros y pinturas del marqués de la Frechilla y Malagón”, Península. Revista de estudios ibéricos, 0 (2003), pp. 261-288.

${ }^{100}$ Cédula de concesión de Título de Marqués de la Frechilla, AHN, Consejos, leg. 9034.

${ }^{101}$ Merced de los Vasallos a don Duarte de Bragança, AHN, Consejo, leg. 9034.

102 Ibidem.

${ }^{103}$ Ibidem.

${ }^{104}$ Ibidem, f. $29 \mathrm{v}$. 
puede percibir no solamente en estos elogios referidos, en las certificaciones de un blasón o la confirmación de unas armas. Un texto destinado a la mayor gloria de la dignidad del monarca puede ser el escenario perfecto para resaltar las calidades de los nobles y dejar memoria escrita de una serie de epítetos con un marcado carácter enaltecedor de la naturaleza de la nobleza en tanto que el lector percibe, mediante las palabras, la calidad y el prestigio social de la nobleza, no ya como cuerpo político sino como realidad sistémica.

Gregorio de San Martín escribió un texto titulado El triumpho más famoso que hizo a la entrada del rey Don Phelippe tercero de España y segundo de Portugal, que se publicó en Lisboa, en la oficina de Pedro de Craesbeeck, en 1623. En el libro aparecen distintos cantos en los que los nobles portugueses, reconocidos por sus apellidos, son glorificados, resaltando las calidades de los mismos. Así, por ejemplo, en el canto XIV se dice que: "son mucho más que Pompeos los Furtados"105, o se reutiliza el tópico de la fortaleza de Hércules y su identificación con la nobleza para referirse a los Guzmanes: "Hércules los Guzmanes invencidos"106, cuando no se recurre a la comparación con personajes ilustres del pasado: "Los Pereras, a Cides comparados" 107 . Igualmente, el vocabulario sobre la nobleza y la identificación de las calidades de los nobles encuentra en la idea de los afectos ${ }^{108}$ hacia el soberano un verdadero palco de exhibición: "Faros, Castros, Martines, Mascareñas/salieron al momento muy gozosos/pasando las montañas y las peñas/a recebir su Rey muy cuidadosos" 109 .

La representación visual de esta narración, además de ser una práctica habitual, quiere ser también un lugar en el que resolver asuntos de prestigio social; antítesis de las palabras con las que se refieren a los no nobles, a los, en definitiva, no honrados:

"Después que los luzeros esparcidos/ Tenía el claro sol que al mundo honor a/ Los nobles portugueses invencidos/ Sus manos van besar al punto y hora./ Del suelo en sus rodillas sostenidos,/ Mostrando la humildad que les corona,/ Los dichos condes hombres celebrados/ Del sitio portuguez los mas honrados". ${ }^{110}$

${ }^{105}$ SAN MARTÍN, Gregorio de: El triumpho más famoso que hizo Lisboa a la entrada del rey don Phelippe tercero de España y segundo de Portugal, Lisboa, Pedro Craesbeeck, 1624 f. 3v.

${ }^{106}$ Ibidem

${ }^{107}$ Ibidem. El recurso a las grandes figuras del pasado para resaltar las virtudes de la nobleza en cualquier momento en un hecho que, por frecuente, no parece menos práctico. No serán solamente los genealogistas los que recurran a ellos; tratadistas de nobleza ofrecerán en su exégesis sobre el concepto de nobleza ejemplos en héroes pasados. Ver GUILLEN BERRENDERO, José Antonio, La idea de nobleza en Castilla, Valladolid, 2007, pp. 25-55.

${ }^{108}$ La importancia de este tipo de lenguajes y otros asuntos referidos a ello han sido tratados magistralmente por CARDIM, Pedro: O poder dos afectos. Ordem amorosa e dinámica política no Portugal do Antigo Regime. Dissertação apresentada à Universidade Nova de Lisboa para a obtenção do grau de Doutor, Universidad Nova, Lisboa, 2000. Texto policopiado.

${ }^{109}$ SAN MARTÍN Gregorio de, op. cit. (nota 106), f. 9v

${ }^{110}$ Ibidem, f. $21 \mathrm{r}$ 
El hecho de que el vocabulario sobre la nobleza presente una jerarquía en los elogios a los principales y que éste resulte de todo punto esencial para su reconocimiento, nos habla de cómo el uso del lenguaje referido a los nobles buscó desde un primer momento los rasgos de distinción precisos, asumiendo que la posición social de lo nobiliario constituía un barómetro sobre el lugar que pertenece a todos y cada uno de los miembros del estamento. Todas o casi todas las familias nobles portuguesas sin distinción de su posición jerárquica construyeron con mayor o menor fortuna una memoria de sí mismas en las que términos como nobres, limpos, illustres, honrados y un largo etcétera de palabras les presentaban como fieles servidores del proyecto representado por los Habsburgo tras la Agregação. En este hecho contribuyó de manera esencial la existencia previa de una literatura genealógica que evidenciaba el peso que la memoria tenía dentro de la identidad nobiliaria portuguesa, pero también la cada vez más evidente influencia de autores nobiliarios castellanos como Otálora, Guardiola, García Saavedra y Moreno de Vargas.

$* * * *$

El vocabulario en torno al concepto del honor nobiliario generó un conjunto de términos que fue utilizado desde la Edad Media para definir lo que era ser noble y lo que no. Palabras que eran manejadas con la misma función tanto por la administración como por los intelectuales en un esfuerzo, quizá conjunto pero, en definitiva, un esfuerzo constante, por dejar claro qué era ser noble y no noble en el Portugal de la Edad Moderna, y cómo y de qué forma se debía actuar para acceder al sistema del honor, valor político que situaba a cada uno de los individuos en aquello que debían hacer en función de su nacimiento, pero que dejaba la puerta abierta a la liberalidad regia para introducir nuevos elementos en este sistema asumiendo que, con ello, se generaba un debate abierto sobre las formas de ennoblecimiento, pero también sobre la propia dimensión pública y social del término noble-nobleza.

La construcción de antinomias, noble/innoble, noble/vil, honrado/sin honra, nobre/ peão y un largo etcétera de términos debe llevarnos a coincidir en que el vocabulario reflejaba cuestiones que iban más allá del propio lenguaje y que afectaban a todos por igual, al tratar esencialmente de asuntos derivados de la idea de prestigio También es importante señalar que la propia construcción pública de la idea de nobleza se hacía jerárquicamente, lo que quiere decir que eran los estratos superiores del estamento nobiliario los que marcaban los elementos del discurso. Eran los valores encarnados por los títulos, duques, condes, marqueses, aquellos que gozaban de un mayor calado social y terminaba por determinar el resto de situaciones nobiliarias. El esfuerzo de los intelectuales, nobilistas, moralistas, y de la propia administración de la monarquía será situar todas las manifestaciones sobre la nobleza dentro de la constitución de un ideal nobiliario que todos deban cumplir a lo largo del tiempo. Donde unos alegan 
antigüedad, otros, que no la posean, introducirán el elemento del esfuerzo personal. La virtud de la sangre a la del servicio. Pero en definitiva, y esto se hará más palpable desde 1640 para el caso portugués, las estrategias de legitimación recurrían al uso de la palabra nobleza y noble para representar cualquier dignidad nobiliaria. Parece que durante el siglo XIX, como ofrece la obra de Pereyra, cuando se produzca una cierta confusión interpretativa de las clasificaciones nobiliarias y, en pos de una clarificación jerárquica de la nobleza, se recurra a atomizar los distintos estratos nobiliarios. No ocurrirá esto en el siglo XVI ni XVII, más bien al contrario, el prestigio en torno a la idea de noble es tal, que todos los individuos desean ser identificados como tales, sobre todo en tanto que éste hecho significa tener reputación social distintiva.

Los elementos constitutivos de la condición de noble en el Portugal de los Habsburgo y sus distintas formas de expresión representan uno de los hitos más significativos al estudiar la evolución de la idea de nobleza. Se trata, en general, de ofrecer una visión meritocrática entorno a la condición nobiliaria, sustanciando los elementos propios de un individuo y el modo en que éstos forman parte sustancial de su condición política. De este modo, la sangre y el servicio articulan una idea de nobleza que legitima tanto a los nobles individualmente como a sus antecesores y sucesores, representando un mecanismo de acceso al honor y una forma de comunicación de lo nobiliario en la que todos sus agentes conocen, comprenden y utilizan un conjunto de códigos apriorísticos que configuran un concepto de noble adaptado a las limitaciones intelectuales de su tiempo, a la tutela de la iglesia y a la acción del creciente poder de los monarcas. Se trata de un hecho afín a la influencia de lo castellano y que marca la evolución que se produce en la progresiva sustitución del mérito por la sangre como marca fundamental de la condición de noble en Portugal. Si bien el peso de lo genealógico ya ocupaba un lugar fundamental en el imaginario nobiliario portugués previo a la Agregação, la influencia de los textos castellanos y de la acción regia terminó por dar forma a una idea de nobleza centrada en la sangre que se extenderá más allá de 1640 pues, con la llegada de los Braganza, se desarrollará una amplia tratadística nobiliaria que insiste en situar a lo hereditario en la cúspide de la condición de noble. El objetivo final de todo este entramado intelectual-administrativo consistía en consagrar, en torno a las palabras nobre-nobreza, fidalgo-fidalguias, una serie de atributos simbólicos, políticos y culturales que sustanciaran la idea de excelencia atribuida a la nobleza portuguesa en su contexto continental.

Hay que destacar, que a pesar de lo aquí expresado, existen sin embargo otros registros en los que la diferencia entre nobres - fidalgo era algo más visible de lo que el marco teórico aquí presentado muestra ${ }^{111}$. Y que este hecho se puede rastrear en

${ }^{\square 0}$ A este respecto deben consultarse los trabajo de MONTEIRO, Nuno Gonçalo, "Casa, reprodução social e celibato: a aristocracia portuguesa nos século XVII-XVIII" en Hispania. Revista española de historia.vol 53, n 185, 1993, pp. 907-936. O también en su "Casa e Linhagem: o Vocabulário Aristocrático em Portugal nos Séculos XVII e XVIII" en Penélope: revista de história e ciências sociais, $\mathrm{nn}^{\circ}$ 12, 1993, pp. 43-64; y "Jerarquía nobiliaria y Corte en Portugal (siglo XV-1832) en MONTERIO, Nuno, CHACÓN JIMENEZ, Francisco (coords), Poder y movilidad social: cortesanos, religiosso y oligarquías en la península ibérica (siglos XV-XIX), Madrid, 2006, pp. 181-214 
una variada tipología documental de carácter administrativo en la que, y en cierta medida, podemos encontrar que durante el siglo XVII el término nobreza refiere a un heterogéneo conjunto de estadios sociales que irían desde personas que poseen algún tipo de atributo y otros que según la historiografía serían un conjunto de individuos que no poseen fidalguia, aunque si nobreza $a^{112}$.

Lo que resulta indiscutible es que los términos nobre y fidalgo remitían a una realidad directamente identificada con el honor y la preeminencia en Portugal y que las distintas formas de identificación social existentes buscarán centrar los parámetros de la reputación identificándola con las tradicionales formas discursivas atribuidas a los nobles en todo el occidente católico, como refleja la tratadística nobiliaria lusitana del periodo ${ }^{113}$.

${ }_{112}$ Entre estos podemos situar a los caballeros de las Órdenes Militares. Ver OLIVAL, Fernanda, Para uma análise sociológica das Ordens Militares no Portugal do Antigo Regime (1581-1621), Tesis de Mestrado. Lisboa, 1988.

113 Ver a este respecto GUILLÉN BERRENDERO, José Antonio, "Honour and service. Álvaro Ferreira de Vera and the ideia of nobility in the Portugal of Habsburgo" en $e-J P H$, number 1, summer 2009. 